\title{
Expression of a clostridial [FeFe]-hydrogenase in Chlamydomonas reinhardtii prolongs photo-production of hydrogen from water splitting
}

\author{
Seth Noone ${ }^{1}$, Kathleen Ratcliff ${ }^{1 \dagger}$, ReAnna Davis ${ }^{1}$, Venkataramanan Subramanian ${ }^{1}$, Jonathan \\ Meuser $^{3 \S}$, Matthew C. Posewitz ${ }^{2}$, Paul W. King ${ }^{1 *}$ and Maria L. Ghirardi ${ }^{1 *}$ \\ ${ }^{1}$ Biosciences Center, National Renewable Energy Laboratory, Golden CO U.S.A. \\ ${ }^{2}$ Department of Chemistry, Colorado School of Mines, Golden CO U.S.A.
}

${ }^{\dagger}$ current affiliation: U.S. Department of Energy, Washington DC

${ }^{\S}$ current affiliation: Algenol, Fort Myers, FL

*corresponding authors email: paul.king@nrel.gov; maria.ghirardi@nrel.gov 


\begin{abstract}
The high oxygen $\left(\mathrm{O}_{2}\right)$ sensitivity of green algal [FeFe]-hydrogenases is a significant limitation for the sustained production of hydrogen gas $\left(\mathrm{H}_{2}\right)$ from photosynthetic water splitting. To address this limitation we replaced the native [FeFe]-hydrogenases with a more $\mathrm{O}_{2}$-tolerant clostridial [FeFe]-hydrogenase Cal

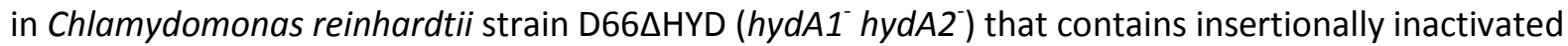
[FeFe]-hydrogenases genes. Expression and translocation of Cal in D66 $\mathrm{HYD}$ led to the recovery of $\mathrm{H}_{2}$ photoproduction at $\sim 20 \%$ of the rates of the wild-type parent strain D66. We show for the first time that a bacterial [FeFe]-hydrogenase can be expressed, localized and matured to a catalytically active form that couples to photosynthetic electron transport in the green alga C. reinhardtii. The lower rates of $\mathrm{O}_{2}$ inactivation of Cal led to more sustained $\mathrm{H}_{2}$ photoproduction when cultures were challenged with $\mathrm{O}_{2}$ or kept under prolonged illumination at solar intensities. These results provide new insights into the requisites for attaining photobiological $\mathrm{H}_{2}$ production from water splitting using a more $\mathrm{O}_{2}$-tolerant hydrogenase.
\end{abstract}

\title{
Keywords:
}

Hydrogen photoproduction, hydrogenase, heterologous expression, $\mathrm{O}_{2}$ tolerance.

\section{Introduction}

The photoproduction of $\mathrm{H}_{2}$ gas by unicellular green algae was discovered 75 years ago and has long held promise as a renewable alternative to non-renewable production from natural gas reforming. The theoretical maximum solar-to- $\mathrm{H}_{2}(\mathrm{STH})$ efficiency of algal photobiological $\mathrm{H}_{2}$ production is $10-13 \%$ of incident solar energy ${ }^{1-3}$, but actual measured efficiencies are around $0.9 \%{ }^{4-6}$ due to several constraints. One limiting factor is the sensitivity of hydrogenase to $\mathrm{O}_{2}{ }^{7-10}$ that results in a rapid and complete inactivation by $\mathrm{O}_{2}{ }^{11,12}$ as well as loss of hydrogenase transcript and protein abundance ${ }^{13-15}$. 
Chlamydomonas reinhardtii is one of the most well-developed model systems for investigating photosynthetic $\mathrm{H}_{2}$ production ${ }^{2,16-18}$. Under anaerobic induction, $\mathrm{C}$. reinhardtii expresses two [FeFe]hydrogenases, HYDA1 and HYDA2 ${ }^{14}$, that couple to photosynthetic electron transport under illumination. To address $\mathrm{O}_{2}$ inactivation there have been efforts to limit the levels of $\mathrm{O}_{2}$ production (i.e., water oxidation) by down-regulation of Photosystem II (PSII) activity through either nutrient deprivation 19 mutations of PSII reaction centers ${ }^{6,20}$ and other gene targets ${ }^{5,21,22}$ or by a combination of nutrient deprivation and physical means ${ }^{4}$. However, each of these strategies lowers the STH efficiency and underscores a need to develop strains and techniques that sustain $\mathrm{H}_{2}$ production without compromising PSII activity levels.

The clostridial [FeFe]-hydrogenase I from Clostridium acetobutylicum (Cal) is known to have a 200fold higher tolerance to $\mathrm{O}_{2}$ compared to the [FeFe]-hydrogenases from C. reinhardtii ${ }^{23}$, suggesting that the exchange of the native algal [FeFe]-hydrogenase for Cal in C. reinhardtii will contribute to more sustained $\mathrm{H}_{2}$ photoproduction in vivo. To investigate this we developed a genetic construct for the nuclear transformation and targeted translocation of Cal to the chloroplast. A C. reinhardtii strain that is defective in the expression of native [FeFe]-hydrogenases, (D66 $\mathrm{HYD}){ }^{24}$ was used as the host strain. We demonstrated that expression of Cal in D66 6 HYD led to the catalytic production of $\mathrm{H}_{2}$ from the coupling of Cal to photosynthetic electron transport. Importantly, when cells were cultured under solar intensities the rates of photosynthetic $\mathrm{H}_{2}$ production were maintained for longer time periods, even at atmospheric levels of $\mathrm{O}_{2}$.

\section{Materials and Methods}

\subsection{Cal expression construct}

Vector pSL18 was digested with Ndel and Xbal and gel-purified with the Qiagen QIAquick Gel Extraction Kit. The sequence of the [FeFe]-hydrogenase I (Cal) gene from Clostridium acetobutylicum ATCC strain 824 was codon-optimized and synthesized for expression in C. reinhardtii. Gene Calv1 
(synthesized by GeneArt) or Calv2 (synthesized by GenScript) were ligated into pSL18 such that their expression was under the control of the $C$. reinhardtii PsaD promoter. Both a circular and an excised version (Fig. S1) were transformed into E. coli strain NovaBlue (Novagen). Transformants were screened by PCR, and plasmid sequences were confirmed by sequencing using the primers 5'GGCCAGGGACGATTATGTATC-3' and 5'-TCCCGTATCAATCAGCGAAAT-3' to the PsaD promoter and terminator sequences.

\subsection{Algal strains and culture conditions}

C. reinhardtii strain D66 (nit', cw15, and $m t^{+}$) was obtained from the Chlamydomonas culture collection center; D66 $\mathrm{HYD}$ (Paro::hydA2, Zeo::hydA1) ${ }^{24}$ was obtained from Dr. Matthew Posewitz at the Colorado School of Mines. The latter was used to create recombinant $C$. reinhardtii expressing the Cal hydrogenase. C. reinhardtii cultures were routinely maintained under $10 \mu \mathrm{E} \mathrm{m}^{-2} \mathrm{~s}^{-1}$ PAR white

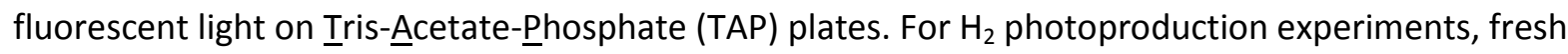
plate stocks ( $<2$ weeks) were used to inoculate $50 \mathrm{~mL}$ of liquid TAP media in $250 \mathrm{~mL}$ Erlenmeyer flasks and grown under the same illumination to an $\mathrm{OD}$ of $15-30 \mu \mathrm{gL}^{-1}$. Enough culture was used to inoculate 500-750 mL of TAP media in Roux bottles at $0.4 \mu \mathrm{g} \mathrm{mL}^{-1}$, and cultures were sparged under stirring with $2 \% \mathrm{CO}_{2}$ at $50-90 \mu \mathrm{E}\left(\mathrm{m}^{-2} \mathrm{~s}^{-1}\right)$ of cool white fluorescent light. Cells were harvested for $\mathrm{H}_{2}$ photoproduction activity during mid-logarithmic growth phase at $10-20 \mu \mathrm{g} \mathrm{Chl} \mathrm{mL}{ }^{-1}$.

\subsection{Nuclear electrotransformation of $C$. reinhardtii and algal cell line generation}

Electrotransformation was performed as outlined in Shimogawara ${ }^{25}$. Briefly, cells were grown to logarithmic phase in TAP media and resuspended to a cell density of $4 \times 10^{8}$ cells $\mathrm{mL}^{-1}$ in TAP+40 mM sucrose medium. A $0.4 \mathrm{~cm}$ BIORAD electrotransformation cuvette was filled with $250 \mu$ l of resuspended cells and 150-750 ng of purified vector DNA was added; the cuvette was then incubated on ice for 10 
min. A $0.8 \mathrm{kV}$ potential with a $25 \mu \mathrm{F}$ capacitance was applied to the cuvette using a BioRad Gene Pulser II electroporation device. Cells were then resuspended in $10 \mathrm{~mL}$ of TAP $+40 \mathrm{mM}$ sucrose and allowed to recover overnight at room temperature in benchtop light ( $10 \mu \mathrm{E} \mathrm{m} \mathrm{s}^{-2}$ of cool white fluorescent) with constant shaking. After centrifugation, cells were resuspended in TAP medium and placed onto three TAP plates containing $15 \mu \mathrm{g} \mathrm{mL} \mathrm{L}^{-1}$ hygromycin, $10 \mu \mathrm{gL}^{-1}$ paromomycin and $7.5 \mu \mathrm{g} \mathrm{mL} \mathrm{L}^{-1}$ zeocin (TAP$\mathrm{ZPH}$ ). Plates were incubated under benchtop light for 1-2 weeks until single colonies could be isolated and re-plated onto TAP-ZPH plates. After a week of growth, cells were assayed for the presence of the plasmid using genomic DNA PCR (see 2.4), or directly for $\mathrm{H}_{2}$ production by the bacterial overlay system (see 2.5). High $\mathrm{H}_{2}$-producing colonies were used to start liquid cultures and grown to logarithmic phase. Cultures were then diluted 1:10000, and spread on TAP-ZPH plates with glass beads. After 1-2 weeks, colonies were assayed again by the bacterial overlay system. High $\mathrm{H}_{2}$-producing colonies were maintained as stocks for further experiments.

\subsection{PCR}

Genomic DNA was isolated using a phenol-chloroform extraction protocol ${ }^{26}$ and digested with the Sca1 restriction enzyme. This DNA was used as template for transformant screening using the primers $F$ (5'-TGCGGTGTGTGCATGGTCGAG-3') and R (5'-GCTGGGAGCCATGGCGACGAT-3'), which yielded a $600 \mathrm{bp}$ product upon successful Cal insertion.

\subsection{Bacterial overlay biosensor system}

Hydrogen photoproduction rates were initially assessed using the biosensor system described by Wecker ${ }^{27,28}$. Briefly, recombinant C. reinhardtii strains were plated onto TAP agar. After two days of growth at RT in $\sim 10 \mu \mathrm{E} \mathrm{m} \mathrm{m}^{-2} \mathrm{~s}^{-1}$ of cool white fluorescent light, plates were overlayed with a Rhodobacter strain expressing the Green Fluorescent Protein (GFP) under the regulation of the native $\mathrm{H}_{2}$-sensing, 
[NiFe]-hydrogenase promoter. Rhodobacter cells $\left(\mathrm{OD}_{660}\right.$ of 0.5$)$ were first mixed in a $\mathrm{M} 1$ media-agar solution before overlaying onto C. reinhardtii plates. The TAP plates were incubated for $24 \mathrm{~h}$ on the bench-top to allow the agar overlay to induce anaerobiosis in the $C$. reinhardtii colonies. Plates were then illuminated and imaged on a Cell Biosciences FluorChem Q system to evaluate GFP (as a proxy for hydrogen production) and chlorophyll fluorescence. Larger GFP fluorescence zones around the spotted C. reinhardtii strains indicate higher $\mathrm{H}_{2}$ production.

\subsection{Photosynthetic $\mathrm{O}_{2}$ and $\mathrm{H}_{2}$ production and dark respiration}

Photosynthetic $\mathrm{O}_{2}$ evolution and respiration rates were measured in actively growing, midlogarithmic (10-20 $\mathrm{g} \mathrm{mL}^{-1}$ Chl) C. reinhardtii cultures as previously described ${ }^{19}$, using a Clark-type Pt$\mathrm{Ag} / \mathrm{AgCl}$ polarographic electrode system ( $\mathrm{ALGI}$, Golden, $\mathrm{CO}, \mathrm{USA}$ ) equipped with a commercially available YSI 5331 electrode (Yellow Springs Instruments, Yellow Springs, OH, USA). The electrode chamber had an illuminated surface area of $1 \mathrm{~cm}^{2}$ and a volume of $2 \mathrm{~mL}$. Actinic light was provided by PAR LEDs at 2,000 $\mu \mathrm{E} \mathrm{m}^{-2} \mathrm{~s}^{-1}$ (equivalent to the PAR region at one sun intensity at noon). For $\mathrm{O}_{2}$ evolution and respiration measurements, aerobic-grown cultures where placed in the Clark electrode chamber, briefly sparged with argon to get rid of oxygen and then subjected to $30 \mathrm{~s}$ in the dark before being illuminated for $2 \mathrm{~min}$ followed by $30 \mathrm{~s}$ in the dark. The second dark period was used to calculate dark respiration, which was then added to the measured $\mathrm{O}_{2}$ evolution estimates to evaluate the actual $\mathrm{O}_{2}{ }^{-}$ evolution capacity of the cultures.

For light-induced $\mathrm{H}_{2}$ measurements, cells were resuspended at 200 or $400 \mu \mathrm{g} \mathrm{mL}^{-1}$ chlorophyll in

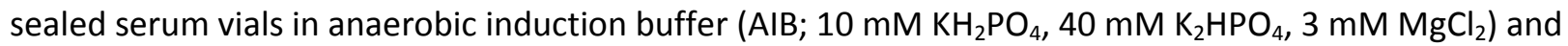
incubated overnight under illumination with $50-90 \mu \mathrm{E} \mathrm{m}^{-2} \mathrm{~s}^{-1}$ cool white fluorescent light and argon sparging. Light induction was required due to regulation of Cal by the light-inducible PsaD promoter. In vivo $\mathrm{H}_{2}$ photoproduction rates were determined as previously described, following illumination for $30 \mathrm{~s}$, 
after a $30 \mathrm{~s}$ dark incubation period ${ }^{4}$. The uncoupler carbonyl cyanide-4-

(trifluoromethoxy)phenylhydrazone (FCCP, $2 \mu \mathrm{M}$ ) was added to the $\mathrm{H}_{2}$-production measurements to prevent inhibition of electron transport by the concomitant accumulation of the proton gradient.

Long-term $\mathrm{H}_{2}$ measurements were conducted as above, except that the cultures were

illuminated for a total period of $30 \mathrm{~min}$. Rates of $\mathrm{H}_{2}$ diffusion were measured in the same manner but in the absence of algal samples. Rates of $\mathrm{H}_{2}$ uptake in the dark were measured immediately after the light was turned off.

\subsection{Hydrogenase protein levels}

Western Blotting performed as previously described ${ }^{29}$. Briefly, equal amounts of total protein were separated on a $10 \%$ SDS-PAGE gel and transferred to a nitrocellulose membrane. Membranes were hybridized with a Cal specific primary antibody raised in rabbit against the Cal peptide sequence $5^{\prime}$ HKLLHVKYTKDKNVSKHE-3' (YenZym, USA), and proteins were detected using the horseradish peroxidase conjugated secondary antibody (GE Healthcare). In parallel, proteins were also stained with Coomassie Blue to be used as a loading control.

\subsection{In vivo $\mathrm{O}_{2}$ sensitivity of hydrogenases}

Cells were evaluated for photosynthetic-hydrogen-production rates in the Clark-type electrode as described above, following exposure to increasing amounts of oxygenated buffer for a total of $30 \mathrm{~s}$ before the light was turned on. Initial rates were estimated based on the initial slope of each curve upon illumination, and the results were fitted to a single (for Cal recombinants) or double exponential decay curve (for native algal hydrogenases) from which half-lives were calculated.

\section{Results and Discussion}


Strain D66 $\triangle$ HYD (hydA1-1 hydA2-1) ${ }^{24}$ is a derivative of wild-type strain D66 that has insertions into each of the HYDA1 and HydA2 structural genes. As a result, D66 $\mathrm{HYD}$ expresses reduced levels of HYDA1 and HYDA2, but retains [FeFe]-hydrogenase maturation capability. Due to the lower expression of native [FeFe]-hydrogenases, D66 $\Delta \mathrm{HYD}$ has severely reduced levels of $\mathrm{H}_{2}$ photoproduction activity of 0.1-0.5\% compared to D66 ${ }^{24}$. We therefore used D66 $\Delta$ HYD as the host for the expression of [FeFe]hydrogenase I from Clostridium acetobutylicum (Cal). A codon-optimized Cal gene was fused to the lightinducible C. reinhardtii PsaD promoter that regulates expression of the PsaD subunit of Photosystem ${ }^{30}$. The Cal coding regions included a ferredoxin (PETF) transit peptide in frame and upstream of the Nterminus of Cal for translocation of Cal into the chloroplast ${ }^{31}$ (Fig. S1). Initially, the circular plasmid was used for transformation. A total of 70 hygromycin-resistant transformants were selected and 10 were screened for the presence of the Cal gene through genomic PCR (Fig. S1). Five positive clones were cultured photoheterotrophically, induced anaerobically, and tested for $\mathrm{H}_{2}$ photoproduction rates. Strain $55 \mathrm{Cal}_{\text {cir }}$ showed the highest rates, up to $8 \%$ of D66 activity and was selected for further study (Table I).

Table I. Photosynthetic parameters for D66 and D66 HHYD Cal expression strains.

\begin{tabular}{|c|c|c|c|c|c|c|}
\hline \multirow[t]{2}{*}{ Strain } & \multirow{2}{*}{$\begin{array}{c}\mathrm{O}_{2} \\
\text { evolution } \\
\text { rate }^{\mathrm{a}}\end{array}$} & \multirow{2}{*}{$\begin{array}{c}\mathrm{O}_{2} \\
\text { respiration } \\
\text { rate }^{\mathrm{a}}\end{array}$} & \multicolumn{2}{|c|}{$\begin{array}{c}\text { Initial } \mathrm{H}_{2} \text { photoproduction } \\
\text { rate }^{\mathrm{a}}\end{array}$} & \multirow[t]{2}{*}{$\begin{array}{c}\text { Inhibition by } \\
\text { DCMU (\%) }\end{array}$} & \multirow{2}{*}{ 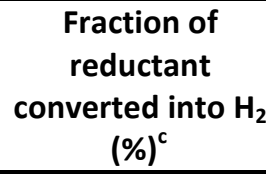 } \\
\hline & & & No Additives & DCMU & & \\
\hline D66 & $\begin{array}{c}154 \pm 10 \\
(n=2)\end{array}$ & $\begin{array}{c}33 \pm 2.7 \\
(\mathrm{n}=4)\end{array}$ & $\begin{array}{c}164 \pm 34 \\
n=6)\end{array}$ & $\begin{array}{l}9 \pm 5 \\
(n=6)\end{array}$ & 94 & 50 \\
\hline $\begin{array}{l}\text { D66 } \\
\text { Cal }_{\text {cir }}\end{array}$ & $\begin{array}{c}59 \pm 16 \\
(38 \%)^{b} \\
(n=4)\end{array}$ & $\begin{array}{l}29 \pm 7 \\
(n=3)\end{array}$ & $\begin{array}{c}13.3 \pm 7.6 \\
(8.0 \pm 4.4 \%)^{\mathrm{b}} \\
\mathrm{n}=15)\end{array}$ & ND & ND & ND \\
\hline $\begin{array}{l}\mathrm{D} 66 \Delta \mathrm{HYD} \\
\mathrm{Cal}_{\mathrm{ex}}\end{array}$ & $\begin{array}{c}53 \pm 7 \\
(35 \%)^{b} \\
(n=4)\end{array}$ & $\begin{array}{l}35 \pm 6 \\
(n=4)\end{array}$ & $\begin{array}{c}35 \pm 22 \\
(21 \pm 13 \%)^{b} \\
(n=4)\end{array}$ & $\begin{array}{l}11 \pm 2 \\
(n=6)\end{array}$ & 69 & 23 \\
\hline
\end{tabular}

${ }^{a} \mu \mathrm{mol} \mathrm{H}_{2}$ or $\mathrm{O}_{2}(\mathrm{mg} \mathrm{Chl} \mathrm{h})^{-1}$. Values are averages of two replicates \pm standard errors, or means \pm standard deviation of more than three replicates (number of replicates shown as " $n$ " in the table). $\mathrm{ND}=$ not determined.

$\mathrm{b} \%$ of wild-type D66. 
${ }^{c}$ Calculated based on (PSII-dependent rate of $\mathrm{H}_{2}$ photoproduction $\times 2$ electrons per $\left.-\mathrm{H}_{2}\right) \div\left(\mathrm{O}_{2}\right.$ evolution rate $\times 4$ electrons per $\left.-\mathrm{O}_{2}\right) \times 100 \%$.

In order to ensure colony homogeneity we used a GFP bioassay (see section 2.5, Materials and Methods) to assess $\mathrm{H}_{2}$ photoproduction activity by Strain $55 \mathrm{Cal}_{\text {cir }}$ after serial propagation and screening under selection. After prolonged growth on selective media, colonies of Strain $55 \mathrm{Cal}_{\text {cir }}$ showed loss of $\mathrm{H}_{2}$ photoproduction (Fig. 1A) and clonal heterogeneity (Fig. 1B). Thus, single colonies originating from the parent transformant colony consisted of mixed populations of hygromycin-resistant cells. Therefore, multiple rounds of propagation and screening were conducted, which resulted in a more homogenous cell line of the Cal expressing Strain 55, designated as Cal $\mathrm{C}_{\text {cir }}$ (Fig. 1C). As previously observed, the measured initial rate of $\mathrm{H}_{2}$ photoproduction by $\mathrm{Cal}_{\text {cir }}$ was $8 \%$ of that of the parent strain (Table I). We addressed the low $\mathrm{H}_{2}$ photoproduction rates by $\mathrm{Cal}_{\text {cir }}$ by excising the non-essential bacterial vector regions of $\mathrm{Cal}^{32}$ to generate $\mathrm{Cal}_{\mathrm{ex}}$ (Fig. S1). Five strains were isolated and analyzed for $\mathrm{H}_{2}$ photoproduction and two were observed to express elevated $\mathrm{H}_{2}$ photoproduction rates that were $\sim 21 \%$ of rates of D66 (Table 1 ).

A

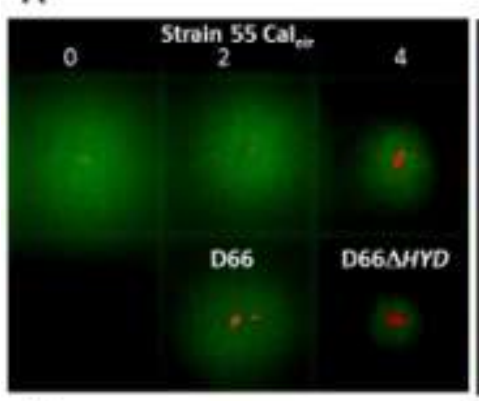

C

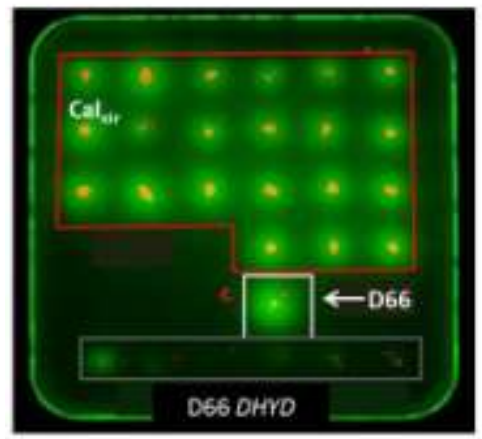

B

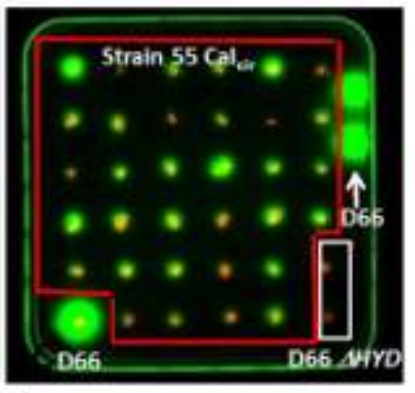

D $\begin{array}{lllllllll}1 & 2 & 3 & 4 & 5 & 6 & 7 & 8 & 9\end{array}$

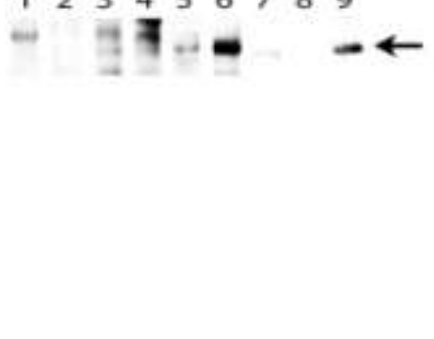


Figure 1. Purification of a stable Cal-expressing Chlamydomonas strain from a heterogeneous population of $\mathrm{Cal}_{\text {cir }}$ transformants. (A) Loss of $\mathrm{H}_{2}$ photoproduction by the $\mathrm{Cal}_{\text {cir }}$ Strain 55 over a period of four months. D66 and the D66 $\triangle \mathrm{HYD}$ strain ( $h y d-$ ) are shown as positive and negative controls, respectively (B) Heterogeneity of $\mathrm{Cal}_{\text {cir }}$ Strain 55 isolates observed using the Rhodobacter overlay $\mathrm{H}_{2}$ sensor system. (C) Stable Cal-expressing Strain 55 (designated as $\mathrm{Cal}_{\text {cir }}$ from now on) colonies after successive rounds of $\mathrm{H}_{2}$-production screening. (D) Western Blot of proteins extracts probed with a $\alpha$-Cal antibody followed by HRP-conjugated secondary antibody and detection with a chemiluminescent substrate. Lanes 1, 3, 5, proteins from oxic cultures of D66, $\mathrm{Cal}_{\mathrm{cir}}$ and $\mathrm{Cal}_{\mathrm{ex}}$ transformant, respectively; lanes 2, 4, 6, proteins from anaerobically induced cultures of D66, Cal $\mathrm{c}_{\text {cir }}$ and Cal $\mathrm{C}_{\mathrm{ex}}$ transformant; lane 7, $1 \mathrm{ng}$ of purified Cal; lane 8, blank; lane 9, 2 ng of purified Cal.

Western blotting analysis compared expression levels of the Cal protein in the Cal $_{\mathrm{ex}}$ strain versus expression in $\mathrm{Cal}_{\text {cir. }}$ Fig. 1D shows that $\mathrm{Cal}_{\text {cir }}$ displayed low levels of Cal expression under both anoxic and oxic conditions (Fig. 1D, lanes 3 and 4, respectively), while the Cal protein from the Cal ex $_{\text {strain was }}$ detected at significantly higher levels under anoxic conditions vs. oxic conditions (Fig. 1D, lane 6 compared to lane 5). At high culture densities, the $\mathrm{O}_{2}$ tension declines, leading to low levels of Cal expression that are detected in cells prior to anaerobic incubation. As shown in Fig. 1D, lanes 5 and 6, the Cal protein is induced several-fold in the $\mathrm{Cal}_{\mathrm{ex}}$ strain and, based on Western Blotting, its level in Cal $\mathrm{ex}_{\mathrm{x}}$ is 6 -fold higher (>6 ng) than in Cal cir (Fig. 1D, lane 4), even when corrected for the total protein level present in each lane (Fig. S3).

We assayed the ability of $\mathrm{Cal}_{\text {cir }}$ to photoproduce $\mathrm{H}_{2}$ following exposure to increasing amounts of added $\mathrm{O}_{2}$. As shown in Fig. 2A, 1 min exposure of cultures to increasing amounts of $\mathrm{O}_{2}$ led to a decay in $\mathrm{H}_{2}$ photoproduction rates for both $\mathrm{D} 66$ and $\mathrm{Cal}_{\text {cir }}$ However, whereas the $\mathrm{H}_{2}$ photoproduction activity was essentially abolished in D66 after exposure to $50 \mathrm{MM} \mathrm{O}_{2}, \mathrm{Cal}_{\text {cir }}$ retained a significant fraction of activity after exposure to near atmospheric levels of $208 \mu \mathrm{M}$. The exponential fits of the decays (Fig. 2B) revealed that D66 inactivates at rates that are $14-285$ fold faster than Cal $_{\text {cir, }}$ confirming previous in vitro results ${ }^{23}$. The range in relative rates is due to the biphasic decays of $\mathrm{H}_{2}$ photoproduction activity in D66 compared to a predominantly monophasic decay in rate for $\mathrm{Cal}_{\text {cir }}$ and takes into consideration the results obtained with a total of four samples. It has been shown that the inactivation of [FeFe]hydrogenase by $\mathrm{O}_{2}$ is dependent on the redox state of the enzyme ${ }^{13,33}$. Due to differences in the 
reduction state populations of the two enzymes under turnover, D66 and $\mathrm{Cal}_{\text {cir }}$ show differences in the $\mathrm{O}_{2}$ inactivation kinetics.

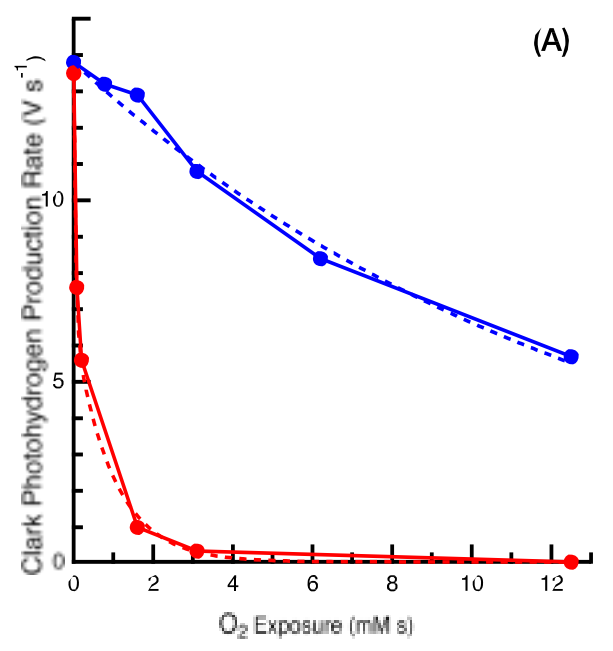

(B)

\begin{tabular}{|l|l|l|}
\hline \multicolumn{1}{|c|}{ Strain } & \multicolumn{2}{|c|}{$\begin{array}{c}\mathbf{O}_{2} \text { inactivation rate } \\
\left(\mathbf{m M ~ O}_{\mathbf{2}} \bullet \mathbf{s}\right)\end{array}$} \\
\hline D66 & $20(51 \%)$ & $1.0(49 \%)$ \\
\hline CaI $_{\text {cir }}$ & $7.0 \times 10^{-2}(100 \%)$ \\
\hline
\end{tabular}

Figure 2. In vivo measurement of hydrogenase $\mathrm{O}_{2}$ tolerance (representative curve of four replicates). (A) Plots of the decay in the $\mathrm{H}_{2}$ photoproduction rates of D66 (-) and $\mathrm{CaI}_{\text {cir }}(-)$ after $\mathrm{O}_{2}$ exposure. Dotted lines are exponential fits. Cultures were anaerobically induced in the presence of $2 \mu \mathrm{M} \mathrm{FCCP}$, and challenged with fixed amounts of $\mathrm{O}_{2}$ saturated buffer. Rates for $\mathrm{Cal}_{\text {cir }}$ were normalized to D66. (B) Table of $\mathrm{O}_{2}$ inactivation constants derived from exponential fits of $(\mathrm{A})$. The inactivation of native [FeFe]hydrogenase activity in D66 fits a double exponential decay $\left(X^{2}=1.3 \times 10^{-7}\right)$, whereas the inactivation of Cal activity fit to a monoexpoential decay $\left(X^{2}=6.2 \times 10^{-7}\right)$.

We measured the rates of photosynthetic electron transport and respiration in wild-type and recombinant strains. Table I shows reduced photosynthetic $\mathrm{O}_{2}$-evolution rates under aerobic conditions by the Cal strains, whereas the respiration rates are similar in all strains. Both water-splitting at 
Photosystem II (PSII) and starch degradation can contribute to the reductant pools required for photosynthetic $\mathrm{H}_{2}$ production. The amount from water splitting in all strains was determined by measuring rates both in the presence and absence of the PSII inhibitor DCMU (3-(3,4-dichlorophenyl)1,1-dimethylurea). As shown in Table I, the addition of DCMU inhibited PSII-dependent $\mathrm{H}_{2}$ photoproduction ${ }^{34,35}$ on $\mathrm{D} 66$ by $94 \%$, whereas $\mathrm{Cal}_{\mathrm{ex}}$ was inhibited by $69 \%$. The residual rates of $\mathrm{H}_{2}$ -

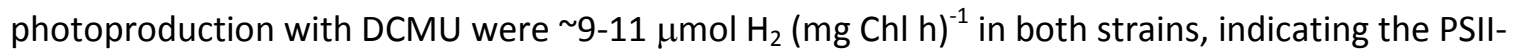
independent rates arising from starch degradation are similar for algal and Cal hydrogenases. PSIIdependent, $\mathrm{H}_{2}$-production rates in $\mathrm{Cal}_{\mathrm{ex}}$ were $16 \%$ of $\mathrm{D} 66$ (48.4 versus $308.8 \mu \mathrm{mol}$ electrons $(\mathrm{mg} \mathrm{Chl} \mathrm{h})^{-1}$, respectively, Table S1) and, given the variation in the measurements, this difference could be attributed to the difference in photosynthetic electron transport rates between $\mathrm{Cal}_{\mathrm{ex}}$ and D66 measured under aerobic conditions (35\%). We also estimated a decreased efficiency of photosynthetic reductant conversion into $\mathrm{H}_{2}$ in the recombinant strain (23 vs. $50 \%$ in D66). Thus, $\mathrm{H}_{2}$ photoproduction in Cal strains is derived from (a) water-splitting at PSII at reduced levels than D66; (b) coupling of Cal to photosynthetic electron transport chain; and (c) reductant from photofermentative starch degradation.

To evaluate whether Cal expression led to more prolonged $\mathrm{H}_{2}$ photoproduction during photosynthetic water splitting and $\mathrm{O}_{2}$ production, strains $\mathrm{Cal}_{\text {cir, }} \mathrm{Cal}_{\mathrm{ex}}$ and $\mathrm{D} 66$ were induced overnight and $\mathrm{H}_{2}$ photoproduction rates were compared over a period of $30 \mathrm{~min}$ (Fig. 3). The initial rate of $\mathrm{H}_{2}$ 


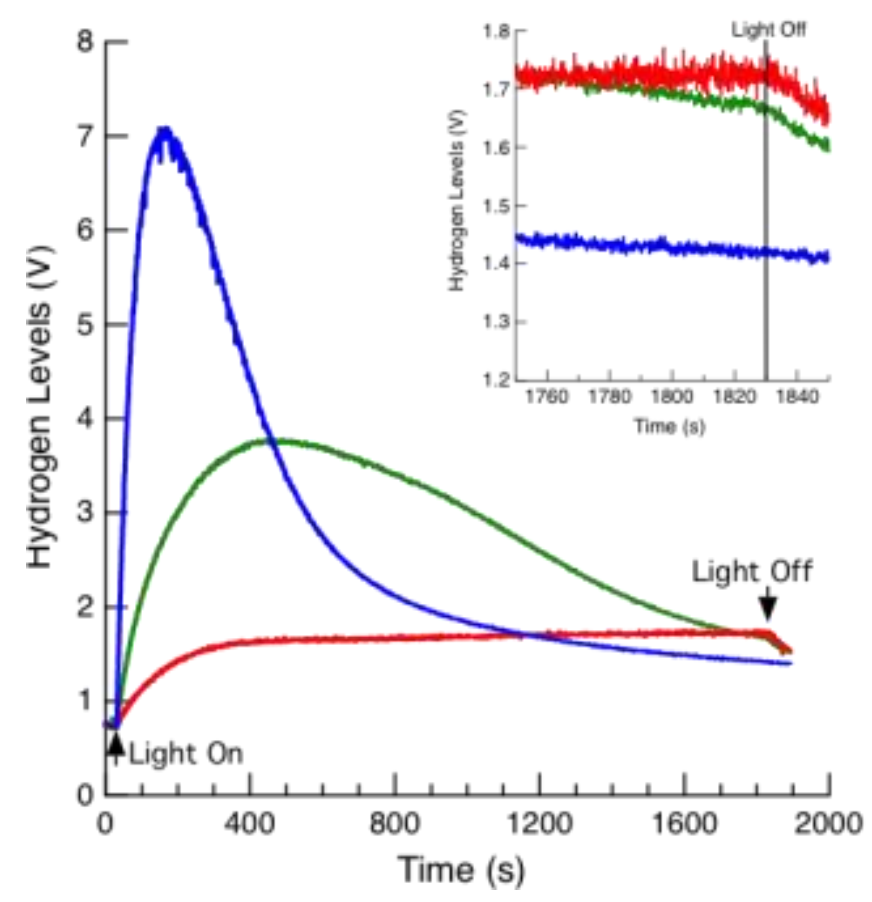

Figure 3. Long-term measurement of $\mathrm{H}_{2}$ levels upon exposure of $\mathrm{D} 66$ (blue), $\mathrm{Cal}_{\text {cir }}$ (red) and $\mathrm{Cal}_{\mathrm{ex}}$ (green) to solar-intensity illumination for a total of $30 \mathrm{~min}$. Insert: decline in $\mathrm{H}_{2}$ levels immediately right before and after the lights are turned off. Notice difference in behavior between D66 and Cal expressing strains. The figure shows representative curves from a total of $7 \mathrm{WT}, 10 \mathrm{Cal}_{\text {cir }}$ and $4 \mathrm{Cal}_{\text {ex }}$ replicates with different Chl concentrations (notice that only those around 20-40 $\mu \mathrm{g} / \mathrm{ml} \mathrm{Chl}$ were used for Table I)

photoproduction by D66 cultures was high during the first few seconds and then declined, due to $\mathrm{H}_{2}$ uptake and eventual loss of hydrogenase activity from $\mathrm{O}_{2}$ inactivation. Maximum $\mathrm{H}_{2}$ accumulation occurred at $\sim 2-3$ min. In contrast, $\mathrm{Cal}_{\text {cir }}$ and $\mathrm{Cal}_{\mathrm{ex}}$ cultures both showed lower initial rates of $\mathrm{H}_{2}$ photoproduction but with a more prolonged decline. In this case, maximum $\mathrm{H}_{2}$ accumulation was observed at $\sim 8$ min. In all cultures, both $\mathrm{H}_{2}$ diffusion out of the chamber and enzymatic $\mathrm{H}_{2}$ uptake by hydrogenase lead to the decline in $\mathrm{H}_{2}$ levels ${ }^{13}$. The measured rate of $\mathrm{H}_{2}$ diffusion was $3.2 \mu \mathrm{mol} \mathrm{H}_{2} \mathrm{~h}^{-1}$ (Fig. S4), a value that is too low to completely account for the observed decline in $\mathrm{H}_{2}$ rates in all three strains. This demonstrates that catalytic $\mathrm{H}_{2}$ uptake is a major contributor to the loss of $\mathrm{H}_{2}$ levels in the reaction cell. Dark rates of $\mathrm{H}_{2}$ uptake were also evaluated (Fig. 3). We observed that Cal remains active throughout illumination and that the decline in $\mathrm{H}_{2}$ levels in the dark was due to a combination of $\mathrm{H}_{2}$ uptake and $\mathrm{O}_{2}$ inactivation of the enzyme (Fig.3, inset; see immediate decrease in $\mathrm{H}_{2}$ levels when the 
light is turned off). In D66, the native algal [FeFe]-hydrogenase is inactivated prior to the end of the illumination period so that no further loss of $\mathrm{H}_{2}$ is observed when the light is turned off (Fig. 3 , inset; see no change in $\mathrm{H}_{2}$ levels after lights are off). These results are in agreement with the differences in $K_{\mathrm{i}}$ for $\mathrm{O}_{2}$ measured for algal versus the Cal hydrogenase ${ }^{13}$.

We determined whether the observed differences between D66 and the Cal strains could be due to the lower $\mathrm{H}_{2}$ photoproduction levels by the Cal strains by testing long-term changes in $\mathrm{H}_{2}$ photoproduction at increasing $\mathrm{Chl}$ concentrations, which should yield increasing levels of photosynthetically-evolved $\mathrm{H}_{2}$ and $\mathrm{O}_{2}$. Both the time required to achieve peak $\mathrm{H}_{2}$ levels and the increased dark $\mathrm{H}_{2}$ uptake rates (observed as a decline in $\mathrm{H}_{2}$ levels after lights are turned off, Fig. S5) follow similar patterns in each Cal strain independent of the Chl concentration. The differences in native versus Cal-expressing strains are attributed to differences in the biochemical properties of algal and clostridial hydrogenases (i.e., higher $\mathrm{O}_{2}$ tolerance and kinetic differences in coupling to ferredoxincatalyzed $\mathrm{H}_{2}$ production and uptake).

We show for the first time that a bacterial [FeFe]-hydrogenase can be expressed, localized and matured to a catalytically active form that couples to photosynthetic electron transport in the green alga C. reinhardtii. The higher $\mathrm{O}_{2}$ tolerance of Cal directly resulted in longer photohydrogen evolution from water splitting. Reductant for photohydrogen production was derived from both photosynthetic water oxidation and photofermentative starch degradation, with each having a differential contribution to the observed rates in the $\mathrm{D} 66$ and Cal strains. Rates of $\mathrm{O}_{2}$ evolution (i.e., photosynthetic water oxidation, Table I) by $\mathrm{Cal}_{\mathrm{ex}}$ strains were $\sim 35 \%$ that of D66, and are consistent with the lower photohydrogen production rates from water oxidation ( $\sim 16 \%$ of PSII-dependent rates in D66) observed under anaerobic conditions. The effect of the absence of native hydrogenases and $\mathrm{H}_{2}$ metabolism on photosynthetic electron transport rates (i.e., rates of $\mathrm{PSII}_{2}$ evolution) under aerobic conditions was not recovered by expression of Cal. This reduced rates of PSII activity partially accounts for the lower photohydrogen 
production rates in Cal-expressing strains (Table 1). Finally, the improved Cal-expression levels in Cal $\mathrm{ex}_{\mathrm{e}}$ versus $\mathrm{Cal}_{\text {cir }}$ led to more efficient conversion of reductant into $\mathrm{H}_{2}(21 \%$ versus $8 \%$, respectively, Table 1$)$. Because our measurements were performed in a 2 ml-volume Clark electrode chamber that has a minimal headspace volume, we could ascertain the effects of $\mathrm{O}_{2}$ and $\mathrm{H}_{2}$ on equilibrium rates and better compare the effect of Cal on $\mathrm{H}_{2}$ metabolism. Preferential $\mathrm{O}_{2}$ binding to HYDA1 under $\mathrm{H}_{2}$ oxidation conditions, and similar $\mathrm{O}_{2}$ inactivation of $\mathrm{H}_{2}$ production and oxidation by HYDA1 ${ }^{13}$ provide the basis for our conclusion that, when expressed in C. reinhardtii, Cal maintains its higher tolerance to $\mathrm{H}_{2}$ inhibition and $\mathrm{O}_{2}$ inactivation, which is evidenced by a prolonged $\mathrm{H}_{2}$ photoproduction rate in the light and lower rates of $\mathrm{H}_{2}$-oxidation (Fig. 3).

Our results unequivocally demonstrate that the successful co-integration of hydrogenases from bacterial microorganisms with microalgae can be achieved for the ultimate purpose of producing renewable $\mathrm{H}_{2}$ fuel from photosynthetic water oxidation to provide a potential alternative to water electrolysis or fermentation. This work shows the introduction of alternative enzymes can be used to address limitations of native biochemical reactions and metabolic pathways. Engineering of enzymes, and enzyme expression, that catalyze conversion of reductant pools into reduced products effectively alters how metabolic pathways integrate with photosynthetic electron transport, and provides a means to resolve regulatory phenomena that control metabolism in photosynthetic systems.

\section{References:}

1 Blankenship, R. E. et al. Comparing photosynthetic and photovoltaic efficiencies and recognizing the potential for improvement. Science 332, 805-809, doi:10.1126/science.1200165 (2011).

2 Ghirardi, M. L., Dubini, A., Yu, J. \& Maness, P. C. Photobiological hydrogen-producing systems. Chemical Society reviews 38, 52-61, doi:10.1039/b718939g (2009).

3 Walker, D. A. Biofuels, facts, fantasy, and feasibility. J Appl Phycol 21, 509-517, doi:10.1007/s10811-009-9446-5 (2009).

4 Kosourov, S. N. \& Seibert, M. Hydrogen photoproduction by nutrient-deprived Chlamydomonas reinhardtii cells immobilized within thin alginate films under aerobic and anaerobic conditions. Biotechnology and bioengineering 102, 50-58, doi:10.1002/bit.22050 (2009). 
$5 \quad$ Kruse, O. et al. Improved photobiological $\mathrm{H} 2$ production in engineered green algal cells. The Journal of biological chemistry 280, 34170-34177, doi:10.1074/jbc.M503840200 (2005).

6 Scoma, A. et al. Sustained $\mathrm{H} 2$ production in a Chlamydomonas reinhardtii D1 protein mutant. Journal of biotechnology 157, 613-619, doi:http://dx.doi.org/10.1016/j.jbiotec.2011.06.019 (2012).

7 Posewitz, M. C., Dubini, A., Meuser, J. E., Seibert, M. \& Ghirardi, M. L. in The Chlamydomonas Sourcebook (Second Edition) (ed Elizabeth H. HarrisDavid B. SternGeorge B. Witman) 217-255 (Academic Press, 2009).

8 Dubini, A. \& Ghirardi, M. L. Engineering photosynthetic organisms for the production of biohydrogen. Photosynthesis research 123, 241-253, doi:10.1007/s11120-014-9991-x (2015).

9 Rupprecht, J. From systems biology to fuel-Chlamydomonas reinhardtii as a model for a systems biology approach to improve biohydrogen production. Journal of biotechnology 142, 1020, doi:http://dx.doi.org/10.1016/i.jbiotec.2009.02.008 (2009).

10 English, C. M., Eckert, C., Brown, K., Seibert, M. \& King, P. W. Recombinant and in vitro expression systems for hydrogenases: new frontiers in basic and applied studies for biological and synthetic H2 production. Dalton transactions, 9970-9978, doi:10.1039/b913426n (2009).

11 Vincent, K. A. et al. Electrochemical Definitions of O2 Sensitivity and Oxidative Inactivation in Hydrogenases. Journal of the American Chemical Society 127, 18179-18189, doi:10.1021/ja055160v (2005).

12 Ghirardi, M., Togasaki, R. \& Seibert, M. Oxygen sensitivity of algal H2- production. Applied biochemistry and biotechnology 63-65, 141-151, doi:10.1007/BF02920420 (1997).

13 Goldet, G. et al. Electrochemical Kinetic Investigations of the Reactions of [FeFe]-Hydrogenases with Carbon Monoxide and Oxygen: Comparing the Importance of Gas Tunnels and Active-Site Electronic/Redox Effects. Journal of the American Chemical Society 131, 14979-14989, doi:10.1021/ja905388j (2009).

14 Forestier, M. et al. Expression of two [Fe]-hydrogenases in Chlamydomonas reinhardtii under anaerobic conditions. European journal of biochemistry / FEBS 270, 2750-2758 (2003).

15 Happe, T., Mosler, B. \& Naber, J. D. Induction, localization and metal content of hydrogenase in the green alga Chlamydomonas reinhardtii. European Journal of Biochemistry 222, 769-774, doi:10.1111/j.1432-1033.1994.tb18923.x (1994).

16 Beer, L. L., Boyd, E. S., Peters, J. W. \& Posewitz, M. C. Engineering algae for biohydrogen and biofuel production. Current Opinion in Biotechnology 20, 264-271, doi:http://dx.doi.org/10.1016/i.copbio.2009.06.002 (2009).

17 Ghirardi, M. L. et al. Hydrogenases and hydrogen photoproduction in oxygenic photosynthetic organisms. Annual review of plant biology 58, 71-91, doi:10.1146/annurev.arplant.58.032806.103848 (2007).

18 Ghirardi, M. L. et al. Microalgae: a green source of renewable H(2). Trends in biotechnology 18, 506-511 (2000).

19 Melis, A., Zhang, L., Forestier, M., Ghirardi, M. L. \& Seibert, M. Sustained photobiological hydrogen gas production upon reversible inactivation of oxygen evolution in the green alga Chlamydomonas reinhardtii. Plant physiology 122, 127-136 (2000).

20 Lin, H.-D. et al. Knockdown of PsbO leads to induction of HydA and production of photobiological H2 in the green alga Chlorella sp. DT. Bioresource technology 143, 154-162, doi:http://dx.doi.org/10.1016/i.biortech.2013.05.101 (2013).

$21 \mathrm{Xu}, \mathrm{F}$. -Q., Ma, W.-M. \& Zhu, X.-G. Introducing pyruvate oxidase into the chloroplast of Chlamydomonas reinhardtii increases oxygen consumption and promotes hydrogen production. International Journal of Hydrogen Energy 36, 10648-10654, doi:http://dx.doi.org/10.1016/j.ijhydene.2011.05.130 (2011). 
Ruhle, T., Hemschemeier, A., Melis, A. \& Happe, T. A novel screening protocol for the isolation of hydrogen producing Chlamydomonas reinhardtii strains. BMC plant biology 8, 107, doi:10.1186/1471-2229-8-107 (2008).

23 Cohen, J. et al. Molecular dynamics and experimental investigation of $\mathrm{H}(2)$ and $\mathrm{O}(2)$ diffusion in [Fe]-hydrogenase. Biochemical Society transactions 33, 80-82, doi:10.1042/BST0330080 (2005).

24 Meuser, J. E. et al. Genetic disruption of both Chlamydomonas reinhardtii [FeFe]-hydrogenases: Insight into the role of HYDA2 in $\mathrm{H}(2)$ production. Biochemical and biophysical research communications 417, 704-709, doi:10.1016/j.bbrc.2011.12.002 (2012).

25 Shimogawara, K., Fujiwara, S., Grossman, A. \& Usuda, H. High-efficiency transformation of Chlamydomonas reinhardtii by electroporation. Genetics 148, 1821-1828 (1998).

26 Gonzalez-Ballester, D. et al. Reverse genetics in Chlamydomonas: a platform for isolating insertional mutants. Plant Methods 7, 1-13, doi:10.1186/1746-4811-7-24 (2011).

27 Wecker, M. S. A., Meuser, J. E., Posewitz, M. C. \& Ghirardi, M. L. Design of a new biosensor for algal $\mathrm{H} 2$ production based on the $\mathrm{H} 2$-sensing system of Rhodobacter capsulatus. International Journal of Hydrogen Energy 36, 11229-11237, doi:http://dx.doi.org/10.1016/i.ijhydene.2011.05.121 (2011).

28 Wecker, M. S. \& Ghirardi, M. L. High-throughput biosensor discriminates between different algal H2 -photoproducing strains. Biotechnology and bioengineering 111, 1332-1340, doi:10.1002/bit.25206 (2014).

29 Fischer, N. \& Rochaix, J. D. The flanking regions of PsaD drive efficient gene expression in the nucleus of the green alga Chlamydomonas reinhardtii. Molecular genetics and genomics : MGG 265, 888-894 (2001).

30 Jin, R., Richter, S., Zhong, R. \& Lamppa, G. Expression and import of an active cellulase from a thermophilic bacterium into the chloroplast both in vitro and in vivo. Plant Molecular Biology 51, 493-507, doi:10.1023/A:1022354124741 (2003).

31 Kumar, A., Falcao, V. R. \& Sayre, R. T. Evaluating nuclear transgene expression systems in Chlamydomonas reinhardtii. Algal Res 2, 321-332, doi:DOI 10.1016/j.algal.2013.09.002 (2013).

32 Swanson, K. D. et al. [FeFe]-hydrogenase oxygen inactivation is initiated at the H cluster $2 \mathrm{Fe}$ subcluster. Journal of the American Chemical Society 137, 1809-1816 (2015).

33 Bishop, N. I., Frick, M. \& Jones, L. W. in Biological Solar Energy Conversion (eds Shigetoh Miyachi, Anthony San Pietro, \& Saburo Tamura) 3-22 (Academic Press, 1977).

34 Biological solar energy conversion / edited by Akira Mitsui ... [et al.]. (Academic Press, 1977).

35 Subramanian, V. et al. Profiling Chlamydomonas metabolism under dark, anoxic H2-producing conditions using a combined proteomic, transcriptomic, and metabolomic approach. Journal of proteome research 13, 5431-5451, doi:10.1021/pr500342j (2014). 
Noone et al. Algal Research submitted 2016

\section{Acknowledgments:}

The authors acknowledge funding from DOE's Fuel Cell Technology Program (S.N., K.R., R.D., V.S., P.W.K. and M.L.G.) and DOE's Office of Science Basic Energy Sciences, Chemical Sciences, Geosciences and Biosciences Division for development of the D66 $\Delta$ HYD strain (J.M., M.C.P., and M.L.G), and the generation of Cal antibodies (S.N., and P.W.K). S.N., K.R., R.D., V.S., P.W.K., and M.L.G. were supported by the U.S. Department of Energy under contract no. DE-AC36-08-GO28308 with the National Renewable Energy Laboratory. 